\title{
High Ringxiety: Attachment Anxiety Predicts Experiences of Phantom Cell Phone Ringing
}

\author{
Daniel J. Kruger, $\mathrm{PhD},{ }^{1}$ and Jaikob M. Djerf ${ }^{2}$
}

\begin{abstract}
Mobile cell phone users have reported experiencing ringing and/or vibrations associated with incoming calls and messages, only to find that no call or message had actually registered. We believe this phenomenon can be understood as a human signal detection issue, with potentially important influences from psychological attributes. We hypothesized that individuals higher in attachment anxiety would report more frequent phantom cell phone experiences, whereas individuals higher in attachment avoidance would report less frequent experiences. If these experiences are primarily psychologically related to attributes of interpersonal relationships, associations with attachment style should be stronger than for general sensation seeking. We also predicted that certain contexts would interact with attachment style to increase or decrease the likelihood of experiencing phantom cell phone calls and messages. Attachment anxiety directly predicted the frequency of phantom ringing and notification experiences, whereas attachment avoidance and sensation seeking did not directly predict frequency. Attachment anxiety and attachment avoidance interacted with contextual factors (expectations for a call or message and concerned about an issue that one may be contacted about) in the expected directions for predicting phantom cell phone experiences.
\end{abstract}

\section{Introduction}

M OBILE CELL PHONE users have reported experiencing ringing and/or vibrations signifying incoming calls and messages, only to find that no call or message had actually registered. These experiences have been variously called "ringxiety," "vibranxiety" "phantom vibrations," "phantom ringing," and "FauxCellArm." Although discussed in the mass media, ${ }^{1}$ there were only 10 scientific studies investigating these phenomena as of October $2014 .^{2}$ Phantom experiences occur for between 27.4 percent and 89 percent of cell phone users across studies. ${ }^{2}$ The relationship between the likelihood of these experiences and the amount of cell phone use is inconsistent across studies. ${ }^{3}$ Among medical staff, four factors predicted experiencing phantom vibrations with pagers and cell phones: younger age, more junior occupational status, carrying the device in one's breast pocket, and proportion of time device is in vibrate mode. ${ }^{4}$

We contacted customer service representatives from cell phone manufacturers, software providers, and network carriers (Apple, Google, Microsoft, AT\&T, Sprint, and Verizon). All denied that hardware, software, or infrastructure issues are the source of these "phantom" experiences. It is possible that some individuals are unknowingly receiving push notifications through their applications, although it is also likely that many of these experiences are what HAL 9000 would describe as "human error." phantom cell phone experiences are in part a human signal detection issue. Human factors, such as experiences, expectations, and physiological states, influence the threshold for signal detection. ${ }^{6}$ A pareidolia is the perception of a familiar pattern in a stimulus, such as the "face" on Mars, where none actually exists. Some phantom cell phone experiences may be a type of pareidolia, and can thus be examined as a psychological phenomenon influenced by individual differences in personality, condition, and context.

Studies on the influence of psychological attributes influencing phantom experiences are rare. One study found that those experiencing phantom vibration and ringing frequently were higher in novelty seeking, but did not differ in harm avoidance and reward dependence, compared to those with less frequent experiences. ${ }^{7}$ As cell phone calls and messages are social interactions, attachment theory ${ }^{8}$ is a framework with good potential to predict and understand phantom cell

${ }^{1}$ School of Public Health, University of Michigan, Ann Arbor, Michigan.

${ }^{2}$ Literature, Sciences, and Arts, University of Michigan, Ann Arbor, Michigan. 
phone experiences. Meta-analysis of attachment research indicates that there are two forms of insecure attachment. ${ }^{9}$ Attachment avoidance is characterized by having discomfort with being close to relationship partners and hiding true feelings from them. Attachment anxiety is characterized by worries about being abandoned by relationship partners and worries that one's feelings for a partner are not reciprocated.

We predict that those higher in attachment anxiety will be more likely to have phantom cell phone experiences, as they crave assurances that partners are interested and invested in the relationship. In contrast, those higher in attachment avoidance may be less likely to have phantom cell phone experiences, as these individuals can be viewed as pushing relationship partners away and, thus, not eager for more interactions with partners. We argue that these experiences are primarily related to the psychology of interpersonal relationships, rather than a general craving for sensory stimuli. Thus, we examine whether there is a relationship between phantom cell phone experiences and general sensation seeking.

We also predicted that certain contexts would interact with attachment style to increase (for attachment anxiety) or decrease (for attachment avoidance) the likelihood of experiencing phantom cell phone calls and messages. These include an expectation of receiving a call or message, anxiety or concern about an issue that one might get a call/ message about, and being unable to respond due to mutually exclusive activities. For comparison, we include one context that may be associated with phantom cell phone experiences in general, but not with attachment dimensions, the recent use of one's cell phone.

\section{Methods}

Ethnically diverse (56 percent indicated some nonWestern European descent) undergraduate students $(N=168$; 94 women and 74 men, $M$ age $=19$ years, $S D$ age $=1)$ from a large public university in the Midwestern USA completed an online survey at their convenience. Participants were recruited from the Psychology Subject Pool and signed up for the study based on an alphanumeric code. Participants were not aware of the study topic before beginning the survey; no participants withdrew from the study. All participants reported carrying and regularly using a mobile phone. Participants first completed brief personality measures. The Experiences in Close Relationships Scale-Short Form (ECR-S) ${ }^{10}$ assesses two dimensions of attachment style, attachment avoidance (six items, Cronbach's $\alpha=0.718$ ), and attachment anxiety (six items, Cronbach's $\alpha=0.792$ ). The Zuckerman-Kuhlman Personality Questionnaire III Impulsive Sensation Seeking (ZKPQ-III-R;11 items, Cronbach's $\alpha=0.897)^{11}$ assessed general sensation seeking.

The next page displayed the item, "Some people have reported phantom vibrations or phantom ringing from their cell phones, when it seems like they get a call or a message, but do not see anything when they check their phones. Has this ever happened to you?" Participants indicated whether or not they experienced "Phantom ringing," "Phantom vibration," and "Phantom notification (image on the screen)." Those who responded "yes" were shown additional items on the next survey page, first asking "How often do you experience phantom ringing?" (etc.). Participants selected text response options: several times a day, about once a day, several times a week, about once a week, several times a month, about once a month, and less than once a month. We created these items based on items commonly used in social and health surveys, such as the Behavioral Risk Factor Surveillance System. Responses were recoded into one numeric variable for each type of phantom sensation, so that "no" $($ Never $)=1$ and "several times a day" $=8$.

On the next page, those who reported phantom phone experiences were asked, "Is this more or less likely to happen when you ..." for the following conditions: "are expecting a call/message," "cannot respond (because you are driving, in class, etc.)," "were on your phone recently," and "are concerned about something that you might get a call/ message about." Response options were "much less likely, less likely, no difference, more likely, and much more likely." All participants indicated the type of mobile phone that they have: touch screen (iPhone, Android, Windows), flip phone (without touch screen), slider phone with a full hard keyboard, older style Palm/Blackberry/etc. with a hard keyboard, other, and do not know). The survey ended with basic demographic items.

\section{Results}

Almost all respondents (165) had a touch screen phone (iPhone, Android, or Windows), two respondents had a flip phone without a touch screen. The most common experience was phantom vibrations ( 82 percent of participants) followed by phantom notification (50 percent of participants) and phantom ringing (45 percent of participants, Table 1). Individuals scoring higher in attachment anxiety had more

Table 1. Frequency Distributions

\begin{tabular}{|c|c|c|c|c|c|c|c|c|}
\hline $\begin{array}{l}\text { How often do you } \\
\text { experience phantom }\end{array}$ & $\begin{array}{l}\text { Several } \\
\text { times } \\
\text { a day }\end{array}$ & $\begin{array}{l}\text { About once } \\
\text { a day }\end{array}$ & $\begin{array}{l}\text { Several } \\
\text { times } \\
\text { a week }\end{array}$ & $\begin{array}{c}\text { About once } \\
\text { a week }\end{array}$ & $\begin{array}{c}\text { Several } \\
\text { times } \\
\text { a month }\end{array}$ & $\begin{array}{l}\text { About once } \\
\text { a month }\end{array}$ & $\begin{array}{l}\text { Less than } \\
\text { once a } \\
\text { month }\end{array}$ & Never \\
\hline \multicolumn{9}{|l|}{ Sample $1, n=168$} \\
\hline Ringing & 0 & $7(4 \%)$ & $7(4 \%)$ & $15(9 \%)$ & $7(4 \%)$ & $15(9 \%)$ & $25(15 \%)$ & $91(55 \%)$ \\
\hline Vibration & $5(3 \%)$ & $14(8 \%)$ & $18(11 \%)$ & $16(10 \%)$ & $23(14 \%)$ & $28(17 \%)$ & $33(20 \%)$ & $30(18 \%)$ \\
\hline Notification & $2(1 \%)$ & $14(8 \%)$ & $13(8 \%)$ & $15(9 \%)$ & $13(8 \%)$ & $8(5 \%)$ & $18(11 \%)$ & $84(50 \%)$ \\
\hline \multicolumn{9}{|l|}{ Sample 2, $n=243$} \\
\hline Ringing & $1(<1 \%)$ & $5(2 \%)$ & $13(5 \%)$ & $11(5 \%)$ & $4(2 \%)$ & $16(7 \%)$ & $20(8 \%)$ & $173(71 \%)$ \\
\hline Vibration & $16(7 \%)$ & $19(8 \%)$ & $21(9 \%)$ & $34(14 \%)$ & $28(12 \%)$ & $33(14 \%)$ & $34(14 \%)$ & $58(24 \%)$ \\
\hline Notification & $14(6 \%)$ & $12(5 \%)$ & $20(8 \%)$ & $15(6 \%)$ & $16(7 \%)$ & $20(8 \%)$ & $11(5 \%)$ & $135(56 \%)$ \\
\hline
\end{tabular}


Table 2. Correlations (Spearman's Rho)

\begin{tabular}{|c|c|c|c|c|c|c|c|}
\hline Trait & $R$ & V & $N$ & $C 1$ & $C 2$ & $C 3$ & C4 \\
\hline \multicolumn{8}{|l|}{ Sample $1, n=168$} \\
\hline Attachment anxiety & $0.180^{*}$ & 0.113 & $0.155^{*}$ & $0.230^{* *}$ & 0.134 & 0.028 & $0.396^{* * *}$ \\
\hline Attachment avoidance & 0.099 & -0.041 & 0.002 & $-0.205^{*}$ & 0.045 & -0.084 & -0.134 \\
\hline Sensation seeking & 0.052 & 0.031 & -0.035 & 0.047 & 0.076 & -0.069 & 0.042 \\
\hline \multicolumn{8}{|l|}{ Sample $2, n=243$} \\
\hline Attachment anxiety & $0.127 *$ & 0.058 & 0.044 & 0.040 & 0.023 & -0.070 & 0.107 \\
\hline Attachment avoidance & 0.015 & 0.018 & -0.065 & $-0.228 * * *$ & -0.086 & -0.085 & $-0.191 * *$ \\
\hline Sensation seeking & 0.009 & -0.017 & -0.099 & -0.120 & 0.031 & 0.136 & -0.001 \\
\hline
\end{tabular}

Note: $* p<0.05 ; * * p<0.01 ; * * * p<0.001$, all two-tailed.

$\mathrm{R}$, ringing; V, vibration; N, notification; C1, "are expecting a call/message"; $\mathrm{C} 2$, "cannot respond (because you are driving, in class, etc.)"; C3, "were on your phone recently"; C4, "are concerned about something that you might get a call/message about."

frequent experiences of phantom ringing and phantom notifications; attachment avoidance and sensation seeking did not predict phantom phone experiences (Table 2). Individuals scoring higher in attachment anxiety were more likely to say that these experiences happened when they were expecting a call or message and when they were concerned about something that they might get a call or message about. Conversely, those higher in attachment avoidance were less likely to report phantom phone experiences when they were expecting a call or message.

\section{Replication}

We replicated the initial study with a new and larger sample of ethnically diverse (56 percent indicated some nonWestern European descent) undergraduate students $(N=243$; 141 women and 102 men, $M$ age $=19$ years, $S D$ age =1) from the same university. Almost all respondents (241) had a touch screen phone (iPhone, Android, or Windows), one respondent had a flip phone without a touch screen, and one respondent had a slide phone with both a touch screen and a full hard keyboard. The most common experience was phantom vibrations (76 percent of participants), followed by phantom notification (44 percent of participants) and phantom ringing (29 percent of participants, Table 1). Mann-Whitney tests determined that experiences of phantom ringing were less frequent in the second sample, $Z=3.19, p<0.001$, although differences were not significant for phantom vibrations or phantom notifications. Individuals scoring higher in attachment anxiety had more frequent experiences of phantom ringing; attachment avoidance and sensation seeking did not predict phantom phone experiences (Table 2). Individuals scoring higher in attachment anxiety were more likely to say that these experiences happened when they were expecting a call or message and when they were concerned about something that they might get a call or message about. Those higher in attachment avoidance were less likely to report phantom phone experiences when they were expecting a call or message and when they were concerned about something that they might get a call or message about.

\section{Discussion}

We demonstrate that the frequency of phantom cell phone experiences is associated with psychological attributes, specifically those related to insecurity in interpersonal rela- tionships. As predicted, those who sought reassurance of partner's interests in their relationship were more likely to experience phantom ringing. Participants who were higher in attachment anxiety were also more likely to experience phantom notifications and were more likely to report these experiences when interpersonal communication was salient in one of the samples. Those motivated to create or maintain psychological distance with relationship partners were actually less likely to experience phantom cell phone experiences when interpersonal communication was salient. In contrast, general sensation seeking did not significantly predict the frequency of phantom cell phone experiences and was unrelated to the influence of contextual factors (including interpersonal communication salience). Also, psychological attributes did not moderate the influence of recency of phone use in predicting phantom cell phone experiences.

We assessed multiple sensory modes of phantom cell phone experiences, auditory, tactile, and visual. Phantom vibration was the most common, experienced by over 75 percent of participants. These stimuli have different properties and are processed by different physiological and cognitive systems. Tactile sensations may be the most ambiguous of these stimuli. User behaviors may also contribute, for example, setting phones to vibration mode when in class and carrying phones in pockets or handbags so the screens are not visible may affect the relative proportions of phantom experiences.

Phantom ringing and phantom notifications in one sample were significantly predicted by attachment anxiety; phantom vibrations may have a real relationship with attachment anxiety that was too weak to be confirmed with the current sample size. The small effects identified by this study are understandable, as the phenomenon measured are qualitatively more different from each other than in many studies of psychological constructs. We would expect to find a stronger relationship between attachment anxiety toward romantic partners and attachment anxiety toward parents, for example. For comparison, the relationship between conscientiousness and phantom vibrations identified by Drouin et al. ${ }^{12}$ corresponds to an $r$-value of 0.15 .

The use of university undergraduates as participants creates the risk that results will not generalize across the population, although there may not be any specific reason why students are not suitable for a test of the hypotheses. Our brief measures may reduce predictive power, although this 
would impede the confirmation of our predictions. Overall, this study provides new insights on human interactions with a rapidly developing technology, in an area where scientific literature is scarce.

\section{Acknowledgments}

The authors thank the Undergraduate Research Opportunities Program for partial funding of this project. They also thank the participants for their time and effort in responding to their survey.

\section{Author Disclosure Statement}

No competing financial interests exist.

\section{References}

1. Parisi D. (2013) Banishing phantoms from the skin: "vibranxiety" and the pathologization of interfacing. Flow 17. http://flowtv.org/2013/01/banishing-phantoms-from-the-skin/ (accessed Feb. 21, 2015).

2. Deb A. Phantom vibration and phantom ringing among mobile phone users: a systematic review of literature. AsiaPacific Psychiatry 2014; 7:231-239.

3. Catchings D, Bush L, Copes B, et al. (2010) Cell phone use and psychological correlates: an explorative study. 2010 Undergraduate Research and Scholarship Conference, Boise, ID. http://scholarworks.boisestate.edu/hs_10/12/ (accessed Feb. 21, 2015).

4. Rothberg M, Arora A, Hermann J, et al. Phantom vibration syndrome among medical staff: a cross sectional survey. British Medical Journal 2010; 341:c6914.

5. Kubrick, S. (Director). (1968). 2001: A Space Odyssey [Motionpicture]. Metro-Goldwyn-Mayer.
6. Tanner WP Jr, Swets JA. A decision-making theory of visual detection. Psychological Review 1954; 61:401-409.

7. Lin Y, Chen C, Li P, et al. A dimensional approach to the phantom vibration and ringing syndrome during medical internship. Journal of Psychiatric Research 2013; 49:12541258.

8. Bowlby J. (1969) Attachment. Attachment and loss, vol. 1. New York: Basic Books.

9. Brennan KA, Clark CL, Shaver PR. (1998) Self-report measurement of adult attachment: an integrative overview. In Simpson JA, ed. Attachment theory and close relationships. New York: Guilford, pp. 46-76.

10. Wei M, Russell DW, Mallinckrodt B, Vogel DL. The Experiences in Close Relationship Scale (ECR)-short form: reliability, validity, and factor structure. Journal of Personality Assessment 2007; 88:187-204.

11. Zuckerman M, Kuhlman, DM, Joireman J, et al. A comparison of three structural models for personality: the Big Three, the Big Five, and the Alternative Five. Journal of Personality and Social Psychology 1993; 65:757-768.

12. Drouin M, Kaiser D, Miller, D. Phantom vibrations in young adults: prevalence and underlying psychological characteristics. Computers in Human Behavior 2012; 28 : 1490-1496.
Address correspondence to: Dr. Daniel J. Kruger School of Public Health University of Michigan 1420 Washington Heights Ann Arbor, MI 48106-1248

E-mail: kruger@umich.edu 
This article has been cited by:

1. Meredith E. David, James A. Roberts, Brett Christenson. 2017. Too Much of a Good Thing: Investigating the Association between Actual Smartphone Use and Individual Well-Being. International Journal of Human-Computer Interaction 3, 1-11. [Crossref]

2. Jon D. Elhai, Robert D. Dvorak, Jason C. Levine, Brian J. Hall. 2017. Problematic smartphone use: A conceptual overview and systematic review of relations with anxiety and depression psychopathology. Journal of Affective Disorders 207, 251-259. [Crossref]

3. Jon D. Elhai, Jason C. Levine, Robert D. Dvorak, Brian J. Hall. 2016. Fear of missing out, need for touch, anxiety and depression are related to problematic smartphone use. Computers in Human Behavior 63, 509-516. [Crossref]

4. Adam B. Csapo, Hunor Nagy, Arni Kristjansson, Gyorgy Wersenyi. Evaluation of human-Myo gesture control capabilities in continuous search and select operations 000415-000420. [Crossref] 